\title{
IoT Trainer Kit Training For Vocational School Teachers As Preparation Towards The 4.0 Industry Era
}

\author{
MAYA RAHAYU, TEDDI HARIYANTO, M. YUSUF FADHLAN \\ Politeknik Negeri Bandung \\ Email: mayarahayu@polban.ac.id
}

Received 28 November 2020 | Revised 30 November 2020 | Accepted 1 December 2020

\begin{abstract}
In welcoming industry 4.0 , teachers in vocational education are required to be able to make students be ready to enter the industry. However, the ability of vocational teachers to replace industry 4.0 is not optimal yet. One of the reason is unavailability of learning media to support IoT-based learning. We use an IoT training kit to make teachers easier to understand the Internet of Things. This trainer kit is equipped with an Arduino, some input devices and communication devices. These features are expected to improve teacher understanding of IoT, making it easier to implement it in the teaching-learning process with their students. The methodology used in this journal is quantitative research, with experimental research designs. The type of experiment used is the type of pre-experimental design, in the form of one group pretest-post-test. The results of this training can improve the learning outcomes from the cognitive realm is $31.45 \%$.
\end{abstract}

Keywords: Training, Trainer Kit, IoT

\section{INTRODUCTION}

Currently, the world is entering the era of the industrial revolution 4.0. In this era, integration between devices using an internet connection is very important. This integration is commonly called the Internet of things (IoT). IoT has influence in various aspects of life, both in the fields of economy, politics, culture, art, and the world of education. In order to prepare Indonesia to face these challenges, it requires qualified human resources supported by education based on this technology as well. SMK as a vocational-based school should have a big role in building human resources to face these challenges. In order to support this, vocational school teachers must have the ability to support the topic of Internet of Things. This is to produce human resources who have skills according to the times. Therefore, various training and supporting equipment are needed to support vocational high school teachers in learning about IoT, which is a new technology. Various studies have been conducted to improve understanding in the field of Electrical Engineering. In (Islam et al., 2010) has used the FPGA / embedded systems training kit to support postgraduate students in short training in industry. In this paper, a kit that integrates software and hardware can help students to understand difficult abstract concepts. In (Mariani et al., 2018), a performance-based adaptive curriculum has been designed for robot training that will assist operations. In this paper, a VR training kit was made for operation using a robot simulation. 
IoT Trainer Kit Training For Vocational School Teachers As Preparation Towards The 4.0 Industry Era

A review of student development using formulas and changing the highest score is obtained from the test results of people who are experts in 
their fields with the minimum score of ordinary people who do not understand at all about robotics. Several other papers also discuss a trainer kit to facilitate the teaching-learning process such as (Pérez et al., 2008) which makes a trainer kit to complement electronic lessons, paper (Noronha et al., 2018) describes a trainer kit to learn in-depth learning about FPGA, paper (Carullo et al., 2003) describes how to use a trainer kit to learning about audio processing, paper (Svane et al., 2017) describes a framework for learning about Arduino, (Cho, 2009) analyzes the educational impact of a trainer kit that has been used as a learning medium. While papers (Luo et al., 2020) and (Kit, 2000) describe and maximize the features of the trainer device. In (Hariyanto et al., 2019) a research was carried out to build a prototype of the IoT trainer kit. The trainer kit integrates software, communication modules and electronic hardware. In this paper, the temperature sensor contained in the IoT trainer kit has been accurate so that the trainer kit can be more reliably implemented as a learning medium. In this journal, the IoT trainer kit will be used as a learning medium for training teachers of SMK Negeri 1 Cimahi. The author wants to know the learning outcomes of the teachers of SMK Negeri 1 Cimahi after training using the IoT trainer kit. It is hoped that after this research, learning outcomes and vocational school teachers' understanding of IoT materials can be improved to face the new challenges of industry 4.0. The results of research in this journal can be used for consideration for various educational institutions, especially vocational education institutions, in selecting learning media to support material understanding of the Internet of Things.

\section{METHOD}

This research was conducted at SMK Negeri 1 Cimahi, with a population of all teachers at SMK Negeri 1 Cimahi, and the research sample was teachers of SMK Negeri 1 Cimahi who attended the IoT Trainer kit training. The data retrieval steps in this journal are described in Figure 1. Before the training was carried out, a sample of 25 students of the Telecommunication Engineering Department of the Bandung State Polytechnic was conducted first. It is assumed that these students have not yet gained an understanding of IoT because they are still studying at the initial level in third semester.

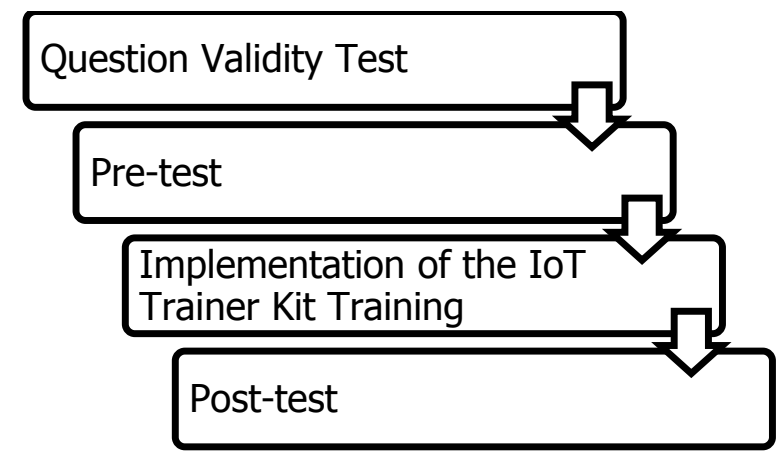

Figure 1. Data Retrieval Steps

The training was conducted for 12 meetings. Each meeting is accompanied by a jobsheet to help trainees understand the material and guide practicum during the training. At the first meeting, a pre-test and preliminary material was carried out which contained an outline of the material as a whole. Then the material content consists of hardware, software and communication media. Table 1 shows the training schedule along with the detailed material provided during the training. The last meeting was filled with post-tests and evaluations. 
Table 1. Details of Training Materials

\begin{tabular}{|c|c|c|}
\hline Meeting & Training Materials & Material Group \\
\hline 1 & $\begin{array}{ll}\text { Pre-test } & \text { and } \\
\text { preliminary } & \end{array}$ & Preliminary \\
\hline 2 & $\begin{array}{l}\text { Mikrokontroler and } \\
\text { Micro SD }\end{array}$ & Hardware \\
\hline 3 & $\begin{array}{l}\text { Communication } \\
\text { Material }\end{array}$ & $\begin{array}{l}\text { Communication } \\
\text { media }\end{array}$ \\
\hline 4 & $\begin{array}{l}\text { Radio } \\
\text { communication }\end{array}$ & $\begin{array}{l}\text { Communication } \\
\text { media }\end{array}$ \\
\hline 5 & Bluetooth & $\begin{array}{l}\text { Communication } \\
\text { media }\end{array}$ \\
\hline 6 & Wi-Fi (ESP 8266) & $\begin{array}{l}\text { Communication } \\
\text { media }\end{array}$ \\
\hline 7 & Node JS & $\begin{array}{l}\text { Communication } \\
\text { Devices }\end{array}$ \\
\hline 8 & HTML and MySQL & Software \\
\hline 9 & PHP & Software \\
\hline 10 & DHT11 Sensor & Hardware \\
\hline 11 & RFID & Hardware \\
\hline 12 & Post-test & Post-test \\
\hline
\end{tabular}

Each training material is accompanied by a training module. Each of these modules is equipped with an introduction, introduction, learning materials, tools / media, materials, learning resources, reading materials, and exercises consisting of work steps. These work steps will help teachers to practice this IoT trainer kit training. In this training, the trainer is assisted by various hardware and software. The hardware, which consists of several tools, is integrated into an iot trainer kit module made by the Bandung State Polytechnic Telecommunication Engineering Department called IoT T-Kit. The image of the IoT T-Kit is in Figure 2. Then the software used is the Arduino IDE to create device control programs as well as various supporting applications for website creation.

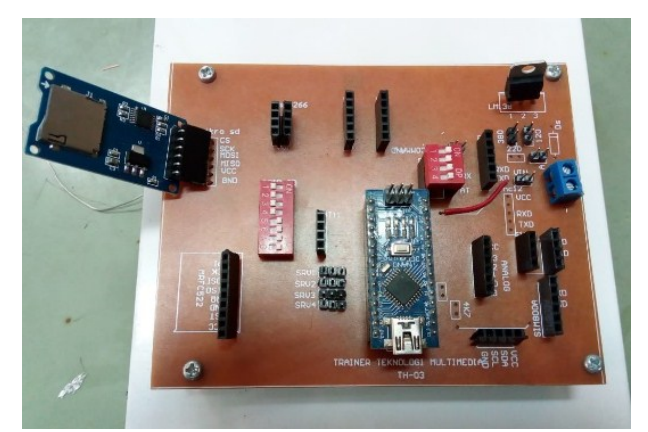

Figure 2. IoT T-Kit (Hariyanto, 2019)

The method used in this journal is a quantitative method. The design used is experimental. The type of experiment used is pre-experimental design, in the form of one group pre-test-post-test. According to (Sugiyono, 2006), a design using this method first performs a pre-test before being treated so that the treatment results can be known more accurately. This is because researchers can compare with the situation before being treated.

Information:

$$
\mathrm{O}_{1} \mathrm{XO}_{2}
$$

01: pre-test, which is carried out before being given training treatment using the IoT Trainer kit learning media.

X: treatment, namely the use of the IoT Trainer kit as a learning medium 
02: the final test (Post-test) which is carried out after the trainer uses learning media using the IoT trainer kit is given.

The variables used in this journal are as follows.

1. Independent Variable $(X)$

Independent variables are often referred to as stimulus, predictor, or antecedent variables. In Indonesian, this variable is often called an independent variable, namely the variable that affects or the variable that causes changes or the emergence of the dependent variable (Sugiyono, 2006). In this journal, the independent variable or independent variable is the use of the IoT trainer kit as a learning medium.

2. Dependent Variable ( $\mathrm{Y}$ )

This variable is often referred to as the output, criterion, or consequent variable. In Indonesian, this variable is often called the dependent variable, which is the variable that is influenced or the variable that becomes the result of the independent variable (Sugiyono, 2006). In this journal the dependent variable is the result of teacher learning in the IoT trainer kit training conducted by the Bandung State Polytechnic. The instruments used in this journal must be tested first. The instrument used was 40 multiple choice items to do the pretest and post-test. There are several methods in testing the instruments used in this journal, namely validity test, reliability test, differentiation test and difficulty level test.

\subsection{Instrument Validity, Reliability, and Distinguishing Tests}

\section{Validity Tests}

The validity test was carried out before the pre-test and post-test were carried out. The validity test was carried out on students of Bandung State Polytechnic level 2 in semester 3 who were assumed to have no understanding of the Internet of Things. Level 2 students have just studied various basic subjects, have not entered the core courses and the subjects studied have not been integrated with one another. To calculate the validity of the instrument by calculating the validity coefficient. The validity test uses the Product Moment Correlation formula (Arikunto, 2002) as follows:

Where:

$$
r_{X Y}=\frac{n\left(\sum X Y\right)-\left(\sum X\right)\left(\sum Y\right)}{\sqrt{\left\{n \sum X^{2}-\left(\sum X\right)^{2}\right\}\left\{n \sum Y^{2}-\left(\sum Y\right)^{2}\right\}}}
$$

$r_{X Y} \quad$ : correlation coefficient

$X \quad$ : each teacher's score on the question item

$\mathrm{Y} \quad$ : the total score of all teachers

$\mathrm{n} \quad$ : the number of teachers

The interpretation of the correlation coefficient in showing the level of validity (Arikunto, 2002) is shown in Table 2.

Table 2. Instrument Validity Criteria

2. Instrument Reliability Test

\begin{tabular}{|c|c|}
\hline Correlation Coefficient & Validity Criteria \\
\hline $0,80 \leq r_{x y}<1,00$ & Very high \\
$0,60 \leq r_{x y}<0,80$ & High \\
$0,40 \leq r_{x y}<0,60$ & Enough \\
$0,20 \leq r_{x y}<0,40$ & Low \\
$0,00 \leq r_{x y}<0,20$ & Very Low \\
\hline
\end{tabular}

The reliability test aims to test the accuracy of the instrument in measuring what will be measured. The reliability test in this journal uses the Kuder-Richardson 21 (K-R20) formula (Arikunto, 2002) as follows: 
Where:

$$
r_{11}=\left(\frac{k}{k-1}\right)\left(\frac{V_{t}-\sum p q}{V_{t}}\right)
$$

r11: Overall test reliability

Vt: Total variance

$\mathrm{k}$ : The number of question items

$\mathrm{p}$ : The proportion of subjects who answered the item correctly

$\mathrm{q}$ : The proportion of subjects who answered the item incorrectly

In finding the price of total variance (Vt) (Arikunto, 2002) it is calculated using the formula below.

Where:

$$
V_{t}=\frac{\sum Y^{2}-\frac{\left(\sum Y\right)^{2}}{N}}{N}
$$

\section{$\Sigma Y \quad$ : Total Score \\ $\mathrm{N} \quad$ : Total Respondent}

The value of $\mathrm{r} 11$ is then compared with the value from the product moment table, if $r 11>r$ table, then the instrument is declared reliable. Conversely, if $r 11$ <rtabel, then the instrument is declared unreliable. The interpretation of the degree of reliability (Arikunto, 2002) is shown in Table 3.

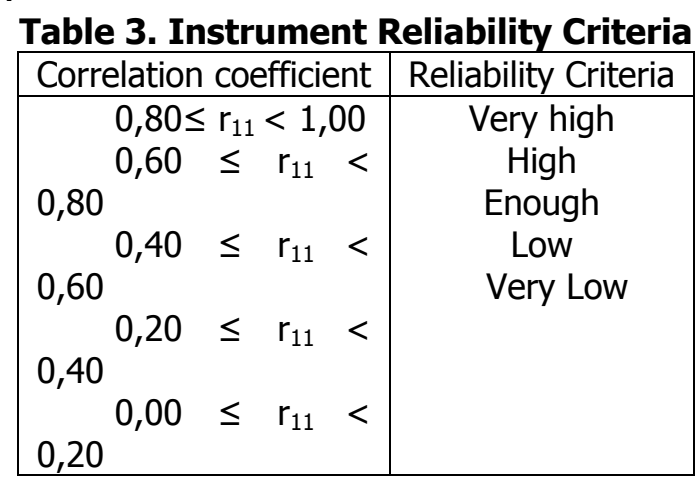

1. The Difficulty Level Test

The difficulty level is a parameter which states that the item is included in the easy, medium, and difficult categories. The difficulty level (Arikunto, 2002) can be calculated by the formula below.

Where:

$$
\mathrm{P}=\frac{\mathrm{B}}{\mathrm{JS}}
$$

P: Difficulty index

$B:$ the number of teachers who answered correctly

JS: the total number of teachers taking the test

\begin{tabular}{|c|c|}
\hline Difficulty Index & Classification \\
\hline $0,30^{0,00 \leq P<}$ & $\begin{array}{l}\text { Difficult } \\
\text { Mediu }\end{array}$ \\
\hline $\begin{aligned} 0,30 & \leq P< \\
0,70 & \\
0,70 & \leq P \leq\end{aligned}$ & Easy \\
\hline
\end{tabular}

The classification of the difficulty index (Arikunto, 2002) can be seen in Table 4.

Table 4. Classification of Difficulty Index

Reka Elkomika- 102 
IoT Trainer Kit Training For Vocational School Teachers As Preparation Towards The 4.0 Industry Era

\begin{tabular}{|l|l|}
\hline 1,00 & \\
\hline
\end{tabular}

If the TK score for a question gets lower, the problem is getting more difficult. A question is said to have a good level of difficulty if the TK obtained from the question is around 0.50 or $50 \%$. Problems with a TK score of $\leq 0.10$ are difficult questions, and those with

a $\quad \mathrm{TK}$

score

of

are

too

easy. 
4. Distinguishing Test

The distinguishing power of a question symbolizes the ability of the question to distinguish between participants in the training who can answer questions and participants who cannot. The distinguishing power classification is in Table 5. The distinguishing power of a problem can be calculated using the formula below.

$$
\mathrm{D}=\frac{\mathrm{B}_{\mathrm{A}}}{\mathrm{J}_{\mathrm{A}}}-\frac{\mathrm{B}_{\mathrm{B}}}{\mathrm{J}_{\mathrm{B}}}=\mathrm{P}_{\mathrm{A}}-\mathrm{P}_{\mathrm{B}}
$$

Where :

$\mathrm{D} \quad=$ Differentiation Index

$\mathrm{J}_{\mathrm{A}} \quad=$ The number of participants in the top group

$\mathrm{J}_{\mathrm{B}} \quad=$ The number of participants in the lower group

$\mathrm{B}_{\mathrm{A}} \quad=$ The number of participants in the upper group who answered correctly

$\mathrm{B}_{\mathrm{B}} \quad=$ The number of participants in the lower group who answered correctly

$\mathrm{P}_{\mathrm{A}} \quad=$ The proportion of participants in the upper group who answered correctly

Table 5. Classification of Distinguishing Power

\begin{tabular}{|c|c|c|}
\hline No. & $D$ Value Range & Classification \\
\hline 1. & $\mathrm{D}<0.20$ & Bad \\
\hline 2 & $0.20 \leq \mathrm{D}<0.40$ & Enough \\
\hline 3. & $0.40 \leq \mathrm{D}<0.70$ & Good \\
\hline 4. & $0.70 \leq \mathrm{D}<1.00$ & Very Good \\
\hline 5 & Negative & Not good, must be thrown away \\
\hline
\end{tabular}

\subsection{Data Analysis Technique}

Then after testing the validity, reliability and discriminating power tests, a new IoT trainer kit training was carried out for vocational school teachers. The training was conducted in 12 meetings, which began with a pre-test and introduction, then ended with a post-test. The training went well and consisted of a total of 38 trainees. The state of training is in Figure 3.

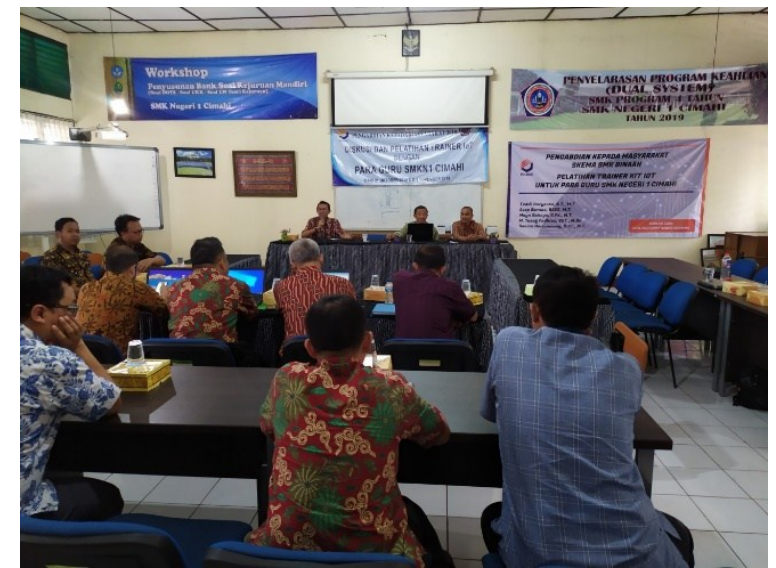

Figure 3. IoT Trainer Kit Training at SMKN 1 Cimahi

Figure 3. The IoT Trainer Kit Training in the data analysis technique using the data normality test, hypothesis testing, and t-value test. SMKN 1 Cimahi.

1. Data Normality Test

The normality test aims to test whether the data tested is normally distributed or not. To obtain normally distributed data, the chi squared distribution test is used. (Arikunto, 2002) The data normality test using Chi-square is done by comparing the normal curve 
formed from the collected data (b) with the standard / standard normal curve (a). To calculate the value of Chi-squared (Arikunto, 2002), several steps are carried out as follows:

1. Determine the number of interval classes for normality testing using Chi-squared, then the number of interval classes is adjusted to the standard normal curve, namely 6 interval classes.

2. Determine the length of the interval class (PK) PK = ((Largest data-Smallest data)) / (Number of interval classes)

3. Create a data frequency distribution table as in Table 6.

Table 6. Frequency distribution table

Where :

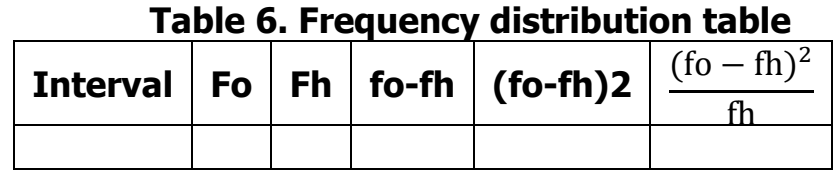

fo: the amount of data observed

fh: expected amount of data

4. Calculated the expected frequency

5. Enter the fh data, and calculate value of (fo - fh ), $\frac{(\mathrm{fo}-\mathrm{fh})^{2}}{\mathrm{fh}}$, and add them up. $\frac{(\mathrm{fo}-\mathrm{fh})^{2}}{\mathrm{fh}}$ is the chi-square value $(x 2)$

6. Comparing the calculated chi-square price with the chi-squared table, with the following conditions: If $x 2$ count $\leq x 2$ table then the data is normally distributed If $x 2$ count $>x^{2}$ table, the data is not normally distributed

7. Hypothesis Testing

Hypothesis testing has a function to determine whether the hypothesis made in this journal is accepted or rejected. The hypotheses proposed in this journal include: HO: the use of the IoT trainer kit as an Internet of Things learning medium is considered effective if the average gain in cognitive learning outcomes obtained by trainees is greater or equal to $30 \%$ $\mathrm{Ha}$ : the use of the IoT trainer kit as an Internet of Things learning medium is considered ineffective if the average gain obtained from the learning outcomes of the trainees' cognitive domain is less than $30 \%$.

$\mathrm{HO} \quad: \Pi \geq 30 \%$

$\mathrm{Ha}:$ : $\Pi<30 \%$

The hypothesis used in this journal is the descriptive hypothesis. Hypothesis testing is done using the left side test.

\section{T Test}

This t test is carried out on the mean value of the pre-test and post-test as well as the gain of the experimental group and the control group. The t test on the pre-test data aims to test whether there are differences in the initial data collection. After the correlation coefficient is known, a significance test is carried out to determine the validity of each question. The significance test (Sugiyono, 2006) was carried out using formula below.

$$
t=\frac{r \sqrt{n-2}}{\sqrt{1-r^{2}}}
$$

Where:
$\mathrm{t}: \mathrm{t}_{\text {calculation }}$
$r \quad$ : correlation coefficient
$\mathrm{n} \quad$ : number of teachers
$T$ test criteria by comparing the results $t_{\text {calculation }}$ with $t_{\text {table. }}$. If $t_{\text {calculation }}>t_{\text {table }}$, then the question can be said to be valid. If $t_{\text {count }}<t_{\text {table }}$ then the question item is said to be invalid. 
IoT Trainer Kit Training For Vocational School Teachers As Preparation Towards The 4.0 Industry Era

$t_{\text {table }}$ obtained from the degrees of freedom $(d k)=n-2$ and the level of significance $(a)=$ 0,05 . 


\section{RESULTS AND ANALYSIS}

The first step taken was making questions to test the validity, reliability, and discriminating power. This trial was conducted to determine the feasibility of the research instrument to be used as a data collection tool. The instrument used in this journal is a multiple choice consisting of 40 questions with 5 choices. Details of the question material as in Table 7.

Table 7. Details of the Material in Problem

\begin{tabular}{|c|l|}
\hline Problem number & \multicolumn{1}{|c|}{ Materials } \\
\hline $1-5$ & Web (HTML and MySQL) \\
\hline $6-10$ & Node JS \\
\hline $11-15$ & PHP \\
\hline $16-25$ & microcontroller (arduino) \\
\hline $25-30$ & Communication Devices \\
\hline $31-35$ & DHT 11 sensor \\
\hline $36-40$ & RFID \\
\hline
\end{tabular}

Of the forty questions, the validity, reliability and discriminating power tests were carried out before they were implemented on the teachers of SMKN 1 Cimahi. The trick is to give these questions to the 2nd level students at the Bandung State Polytechnic. It is assumed that these students do not have an understanding of IoT. The test results from these students were then processed to test the validity, reliability and discriminatory power.

\subsection{Instrument Test}

1. Validity test results

The calculation of the instrument validity test in this journal uses Product Moment correlation. In this study, there were 40 questions whose validity was tested, with a total of 25 students. The confidence level is $95 \%$ with degrees of freedom ( $d k)=23$ ( $d k=n-2=$ $25-2=23$ ). Then obtained $t_{\text {table }}=1,7$. The items of the instrument are declared valid if $t_{\text {calculation }}>t_{\text {table. }}$.

Based on the results of the instrument validity test, 31 questions were found to be valid and 9 questions were invalid. A total of 9 questions were eliminated so that the questions to be used as instruments became 31 questions. The validity data of these instruments are shown in Table 8.

Table 8.The Results of Problem Validity Test

\begin{tabular}{|l|l|l|}
\hline \multicolumn{1}{|c|}{ Validity } & \multicolumn{1}{|c|}{$\begin{array}{c}\text { Numbers of } \\
\text { Question }\end{array}$} & \multicolumn{1}{c|}{ Question Number } \\
\hline Valid & 31 & $\begin{array}{l}1,2,3,4,5,7,8,9,10,11,13,15,16,17,19,20,21,22,23,24, \\
25,26,28,30,32,34,35,36,37,38,39\end{array}$ \\
\hline Not Valid & 9 & $6,12,14,18,27,29,31,33,40$ \\
\hline Total & & \multicolumn{2}{c|}{40} \\
\hline
\end{tabular}

2. Reliability Test Results

The results of the calculation of the reliability test on a sample of 25 students using the Kuder-Richardson formula. This reliability test uses a significance level of $5 \%$ and degrees of freedom $(\mathrm{dk})=23(\mathrm{dk}=\mathrm{n}-2=25-2=23)$. Then obtained $r_{\text {table }}$ equal to 0,31 . The instrument can be said to be reliable if $r_{\text {calculation }}>r_{\text {table. Details of the reliability test results }}$ are in Table 9.

Table 9. Reliability Test Results 
IoT Trainer Kit Training For Vocational School Teachers As Preparation Towards The 4.0 Industry Era

\begin{tabular}{|c|c|c|c|}
\hline$r_{12}$ & $r_{11}$ & $r_{\text {tabel }}$ & Notes \\
\hline 0.80 & 0.89 & 0.31 & Reliable with very high criteria \\
\hline
\end{tabular}

From the results of the calculation of the reliability test in this journal, it can be said that the research instrument is declared reliable. This means that if this instrument is used several times to measure the same object, it will produce the same data, where $r_{11}(0,89)>$ $r_{\text {table }}(0,553)$.

3. Difficulty Level Test Results

Test the difficulty level of the test questions for 5 choice multiple choice questions was carried out to determine the level of difficulty of each item that had been declared valid. The results of the difficulty level test can be seen in Table 10.

Table 10. Test Results of Problem Difficulty Level

\begin{tabular}{|c|c|c|}
\hline Criteria & Numbers of Question & Question Number \\
\hline Easy & 2 & 38,39 \\
\hline Medium & 26 & $1,2,3,4,5,7,8,9,10,11,13,15$, \\
& & $17,19,20,21,22,24,25,26,28,30$, \\
& & $34,35.36,37$ \\
\hline Difficult & 3 & $16,23,32$ \\
\hline
\end{tabular}

4. Distinguishing Power Test Results

The distinguishing power test was conducted to determine the ability of the questions to differentiate between smart, poor and moderate groups of training participants. The results of the distinguishing power test for each question can be seen in Table 11.

\begin{tabular}{|} 
Table 11. Distinguishing Power Test Results \\
\hline Classification & $\begin{array}{c}\text { Numbers } \\
\text { of } \\
\text { Question }\end{array}$ & $\begin{array}{c}\text { Question } \\
\text { Number }\end{array}$ \\
\hline Good & 7 & $\begin{array}{c}7,21,22,25, \\
28,32,35\end{array}$ \\
\hline & & $1,2,3,4,5,8$ \\
Medium & 21 & $\begin{array}{c}11,13,13,15,20 \\
23,24,26,27 \\
\end{array}$ & & $30,34,36,37$ \\
\hline Bad & 3 & $10,38,39$ \\
\hline
\end{tabular}

\subsection{Data Analysis}

1. Pre-test Results

The pre-test results provide an overview of the training participants' initial abilities before obtaining material about the Internet of Things. For more details, the pre-test result data can be seen in Table 12.

Table 12. Description of Pre-test Data

2. Post-test Results

\begin{tabular}{|c|c|}
\hline Number of Samples & 38 \\
\hline Minimum Score & 11,0 \\
\hline Maximum Score & 93,5 \\
\hline Range $(\mathrm{R})$ & 82,55 \\
\hline Average $(\bar{x})$ & 52,84 \\
\hline
\end{tabular}


IoT Trainer Kit Training For Vocational School Teachers As Preparation Towards The 4.0 Industry Era

The results of the post-test will provide a partial picture of the final abilities of the training participants after obtaining the subject matter (treatment). The post-test results were obtained 
from a written test with the same type of test and the number of questions as the pre-test. The post-test result data is described in Table 13.

Table 13. Post-test Result Data

\begin{tabular}{|c|c|}
\hline Number of Samples & 38 \\
\hline Minimum Score & 54,8 \\
\hline Maximum Score & 100,00 \\
\hline Range (R) & 45,16 \\
\hline Average $(\bar{x})$ & 81,84 \\
\hline
\end{tabular}

3. Cognitive Gain

Gain data obtained from the pre-test and post-test results of the training participants. The next data analysis will then be carried out on the data gain. The gain data in this study are listed in Table 14.

Table 14. Gain data obtained by training participants

\begin{tabular}{|c|c|c|}
\hline Pre-test & Postest & Gain \\
\hline $50.39 \%$ & $81.84 \%$ & $31.45 \%$ \\
\hline
\end{tabular}

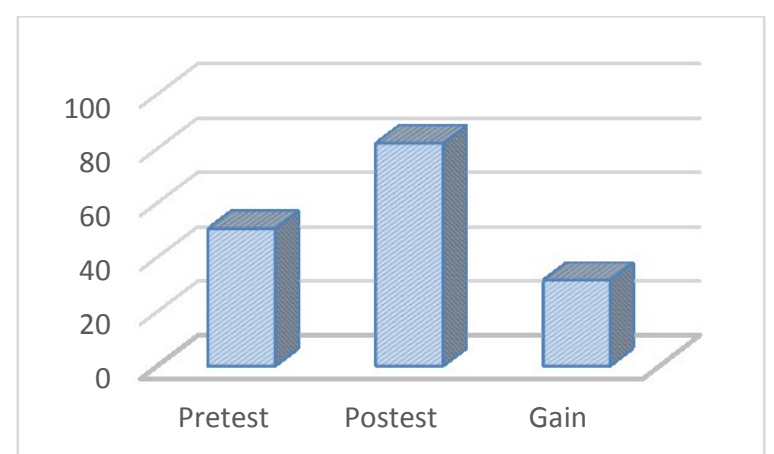

Figure 4. Comparison of Pre-test and Post-test Results

The comparison of the pre-test and post-test results is in Figure 4. From this graph, it can be seen that the average pre-test result of the training participants was $50.39 \%$, while the posttest average was $31.84 \%$. Based on these data, it can be concluded that the use of the IoT trainer kit is quite effective because of an increase in teacher learning outcomes in the cognitive domain of $31.45 \%$.

4. Normality Tests Result

From the results of the normality test that has been carried out on the pre-test and post-test results, data is obtained as in Table 15 below.

Table 15. Data Normality Test Results

\begin{tabular}{|l|c|c|}
\hline & $X^{2}$ calculation & $X^{2}$ table \\
\hline Pre-test & 10,07 & 11,07 \\
\hline Post-test & 10.83 & 11,07 \\
\hline
\end{tabular}

In the table above, it can be seen that the $\times 2$ count in the pre-test is 10.07 . Meanwhile, in the post-test, the $x 2$ count was 10.83 . With $\mathrm{dk}=6-1=5$ at the $95 \%$ 
confidence level, it is obtained $x 2$ table $=11.07$. Data can be stated as normal if $\times 2$ count $>$ 2table. Therefore, the pre-test and post-test data were declared normal.

\section{Hypothesis Test Results}

Hypothesis testing in this journal is conducted to determine the effectiveness of using the IoT trainer kit as a learning medium. Hypothesis testing in this journal is by using the left side test. The hypotheses in this journal are as follows:

$\mathrm{HO}$ : the use of IoT trainer kits as an Internet of Things learning medium is considered effective if the average gain of student learning outcomes is greater than or equal to $30 \%$

$\mathrm{Ha}$ : the use of the IoT trainer kit as an Internet of Things learning medium is considered ineffective if the average gain of learning outcomes in the cognitive domain of the trainees is less than $30 \%$.

$\mathrm{HO} \quad: \Pi \geq 30 \%$

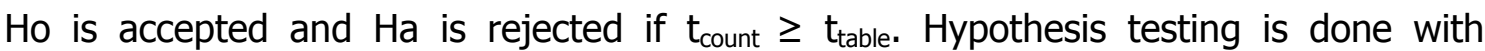
degrees of freedom $(\mathrm{dk})=\mathrm{n}-1=38-1=37$ with an error rate of 0.05 in order to obtain $t_{\text {table }}=-2.68$. $t_{\text {count }}$ is 1.479 . Because of $t_{\text {count }}(1,479) \geq t_{\text {table }}(-2.68)$, then $H 0$ is accepted and $\mathrm{Ha}$ is rejected. So that the use of the IoT trainer kit as a learning medium is considered effective.

After performing various data processing, several findings were obtained. The first finding was that some of the items on the instrument did not meet the requirements to be used as a measuring tool for the training participants' ability tests. This is due to the low Rpbis so the value $r_{\text {count }}$ compared with $r_{\text {table }}$ be low. A question can be said to be invalid because the question is too easy, causing almost all training participants to answer correctly or the item is too difficult so that the trainee cannot answer correctly. This causes $r_{\text {count }}$ to be smaller than $r_{\text {table }}$ which means that the item is invalid. Although the results of the validity test showed that there were several items that were invalid, based on the results of the reliability test, the instrument was declared reliable. This shows that the items that are declared valid can be used for research instruments.

From the results of the difficulty level test, most of the questions on the research instruments in this journal were included in the moderate criteria. Then, based on the results of the distinguishing power test, it showed that most of the items had good and sufficient criteria. The average pre-test training participants was 50.39, while the post-test mean training participants was 81.84. The gain obtained from the learning outcomes of the training participants was 31.45. From these data, showing an increase in learning outcomes from the sample is part of the moderate criteria. This shows that the improvement in learning outcomes before training and after training has changed, but it is not too significant. As for the results of research on this IoT trainer kit training, there are several advantages and disadvantages. One of the advantages is that it is easy to implement, efficiency in time and energy because teachers in the learning process do not need to provide many devices for learning IoT.

Trainer kit devices are integrated so there is no need for too much wiring. The second advantage is that the use of the IoT trainer kit makes it easier for teachers to integrate understanding the IoT concept and integrate between software, hardware and communication. The problem with using the IoT trainer kit when used as a learning medium is that some IoT trainer kit software sometimes cannot be installed on a certain OS, so the use of the software and OS versions must be determined so that teachers do not experience difficulties. In addition, not all teachers bring laptops during training which causes reduced understanding. 


\section{CONCLUSIONS}

By using the IoT trainer kit in the cognitive domain, it can be said to be effective because the average gain in learning outcomes in the cognitive domain of teachers is $31.45 \%$. This is supported by material regarding software, hardware and communication devices that have been well integrated in the IoT trainer kit and the accompanying jobsheet. With significant results in IoT learning for these training participants, the IoT trainer kit is a learning medium that is good enough to support material understanding of the Internet of Things in the scope of Vocational Education.

\section{ACKNOWLEDGEMENT}

Thank you to SMK Negeri 1 Cimahi and all of its teachers, especially teachers who have participated in the IoT Trainer kit training by Bandung State Polytechnic.

\section{LIST OF REFERENCES}

Arikunto, Suharsimi. (2002). Prosedur Penelitian Suatu Pendekatan Praktek. Jakarta : Rineka Cipta.

Carullo, A., Parvis, M., \& Vallan, A. (2003). An audio card-based kit for educational purposes. IEEE Transactions on Instrumentation and Measurement, 52(3), 733-737.

Cho, S. Y. (2009). A virtual simulation package for Embedded System training and education. 2009 International Conference on Engineering Education, ICEED2009 - Embracing New Challenges in Engineering Education, ICEED, 72-76.

Hariyanto, T., Rahayu, M., Satria, F., \& Fadhlan, M. Y. (2019). Improving Temperature Sensor Accuracy in the IoT Trainer Kit by Linear Regression Method. Proceedings of the 2019 International Conference on Mechatronics, Robotics and Systems Engineering, MoRSE 2019, December, 237-240.

Islam, S. Z., Jidin, R. Bin, Islam, S. Z., \& Hamid, F. A. B. (2010). FPGA/Embedded system training kit targeted to graduate students towards industry level short training. 2010 IEEE Education Engineering Conference, EDUCON 2010, 1159-1163.

Kit, I. T. (2000). PWM-CAD1: An. 00, 780-785.

Luo, C., Sit, M. K., Fan, H., Liu, S., Luk, W., \& Guo, C. (2020). Towards efficient deep neural network training by FPGA-based batch-level parallelism. Journal of Semiconductors, 41(2), 1-8.

Mariani, A., Pellegrini, E., Enayati, N., Kazanzides, P., Vidotto, M., \& De Momi, E. (2018). Design and Evaluation of a Performance-based Adaptive Curriculum for Robotic 
IoT Trainer Kit Training For Vocational School Teachers As Preparation Towards The 4.0 Industry Era

Surgical Training: A Pilot Study. Proceedings of the Annual International Conference of the IEEE Engineering in Medicine and Biology Society, EMBS, 2018-July, 21622165.

Noronha, D. H., Leong, P. H. W., \& Wilton, S. J. E. (2018). Kibo: An open-source fixed-point tool-kit for training and inference in FPGA-based deep learning networks. Proceedings - 2018 IEEE 32nd International Parallel and Distributed Processing Symposium Workshops, IPDPSW 2018, 178-185.

Pérez, D., Balcells, J., Lamich, M., Berbel, N., Zaragoza, J., \& Mon, J. (2008). Training kit for power electronics teaching. IECON Proceedings (Industrial Electronics Conference), 3541-3545.

Sugiyono. (2006). Statistika Untuk Penelitian. Bandung : CV Alfabeta.

Svane, T. E., Zhu, M., Johansson, L. O., \& Ebbesson, E. (2017). Like a snowball: Adding layers of knowledge Enchanting student work with student input. 2017 16th International Conference on Information Technology Based Higher Education and Training, ITHET 2017, c. 